\title{
LA JOLLA MEASUREMENTS OF RADIOCARBON IN THE OCEANS
}

\author{
T W LINICK
}

Mt Soledad Radiocarbon Laboratory, Department of Chemistry, University of California, San Diego, La Jolla, California 92093

\section{INTRODUCTION}

The La Jolla Radiocarbon Laboratory has measured carbon-14 concentrations in seawater samples collected from 1957 through 1972. The dissolved inorganic carbon in seawater was extracted on board research vessels and was returned to the laboratory for processing and measurement. Both surface and sub-surface samples were collected, primarily from the Pacific Ocean, but also from the Indian Ocean. The purpose of the seawater measurements was to determine the distribution of bombproduced radiocarbon in the surface water of the Pacific and Indian Oceans, the sub-surface penetration of bomb ${ }^{14} \mathrm{C}$, the change in ${ }^{14} \mathrm{C} /{ }^{12} \mathrm{C}$ ratios with depth, and thus the rate of uptake of bomb ${ }^{14} \mathrm{C}$ by the oceans. This project was the basis of the author's doctoral dissertation (Linick, 1975).

The carbon dioxide of the atmosphere is constantly in exchange with the dissolved inorganic carbon of the sea, the oceans containing ca 60 times the amount of carbon dioxide found in the atmosphere (Revelle and Suess, 1957; Craig, 1958). This dissolved inorganic carbon is primarily in the form of bicarbonate because of the equilibrium constants of the aqueous carbon system. Prior to this century, both the quantities of dissolved inorganic carbon and the concentrations of carbon-14 were under approximately steady state conditions, as the atmospheric $\mathrm{CO}_{2}$ concentration and the natural production rate of ${ }^{14} \mathrm{C}$ were approximately constant. Secular variations in the ${ }^{14} \mathrm{C}$ production rate and perhaps also changing oceanographic conditions have caused variations of up to $10 \%$ in the atmospheric ${ }^{14} \mathrm{C}$ levels during the past 7000 years (Suess, 1970). Since the beginning of this century, man has added sufficient ${ }^{14}$ C-free carbon dioxide from the combustion of fossil fuels to increase measurably the concentration of carbon dioxide in the atmosphere and to decrease the atmospheric ${ }^{14} \mathrm{C} /{ }^{12} \mathrm{C}$ ratio; these quantities have also changed somewhat in surface seawater. Since 1954, the detonations of nuclear weapons, particularly the tests of the USA and USSR in 1961 and 1962, have released large quantities of additional radiocarbon into the atmosphere. The measurements of seawater samples monitored the transfer of this bomb-produced radiocarbon from the atmosphere into the oceans. In addition to the La Jolla measurements, seawater ${ }^{14} \mathrm{C}$ programs have been carried out by the New Zealand laboratory of $T A$ Rafter, which measured samples from the South Pacific (Rafter, 1968; Rafter and O'Brien, 1970; Rafter and O'Brien, 1972), the Lamont laboratory of W S Broecker, which measured samples from the Atlantic 
Ocean (Broecker and Olson, 1959; Broecker et al, 1960), and by several laboratories in Europe.

The sampling for this laboratory was performed primarily from research vessels of the Scripps Institute of Oceanography (SIO). Generally, 200 to 225L of seawater were obtained for each sample, almost filling a polyethylene-lined steel drum. Surface water was usually collected through a non-contaminating seawater pumping system aboard the ships; in such cases the water samples came from a few meters below the sea surface at the ship's bow. Several different systems involving metal barrels with remote closing devices were used for collection of sub-surface samples. Collection of sub-surface samples (depth profiles) had to be terminated after 1965, because continuation of funding of sub-surface water collection was denied by the U S Atomic Energy Commission. The carbon dioxide was extracted aboard the ship: The seawater was acidified with sulfuric acid and heated to $\mathrm{Ca} 50^{\circ} \mathrm{C}$. The $\mathrm{CO}_{2}$ was absorbed in ca $0.70 \mathrm{~L}$ of a solution ca $15 \mathrm{~F}$ in $\mathrm{NH}_{4} \mathrm{OH}$ and $1 \mathrm{~F}$ in $\mathrm{SrCl}_{2}$. The extraction system used for the last several years of sample collection involved recirculating for at least four hours the small amount of air above the seawater through a diffuser head immersed in the sealed bottle containing the absorber solution and returning the air (with seawater carbonate removed) to the drum via a diffuser head immersed deep into the water in the drum; a Masterflex peristaltic pump was used for this gas recirculation. The inorganic carbon originally dissolved in the seawater and then in the form of $\mathrm{CO}_{2}$ gas was swept from the drum by the air and dissolved in the absorber solution. The absorber bottle containing the $\mathrm{SrCO}_{3}$ precipitate plus absorber solution was sealed and eventually returned to the laboratory for processing. In the laboratory, the solution was decanted and the precipitate dried under vacuum. The SrCOO was then reacted with $2 \mathrm{~F}$ HCl on the high vacuum lines; the resulting $\mathrm{CO}_{2}$ was converted to acetylene, our counting gas, in the usual manner. The method, detectors, and electronics used are those described by Linick (1977). Counting pressures from 400 to $1000 \mathrm{~mm} \mathrm{Hg}$ were utilized.

The ocean-atmosphere carbon system is quite complex. The atmospheric $\mathrm{CO}_{2}$ exchanges at the ocean surface with that dissolved in the seawater. Once in the surface water, or so-called mixed layer, of the ocean, the distribution of dissolved $\mathrm{CO}_{2}$ is dependent on several factors: (1) the horizontal movement of water currents; (2) the vertical movement of water, $i c$, upwelling and downwelling; (3) the stratification of water masses (eg, the barrier to exchange formed by the thermocline at the bottom of the mixed layer; (4) horizontal and vertical diffusion; and (5) particulate flux, $i e$, the incorporation of "new" $\mathrm{CO}$. by near-surface organisms, transfer via the food chain, and eventual descent (and possible dissolution en route) of dead matter to the sea floor.

The data presented here constitute all of the seawater sample measurements by this laboratory from 1957 through 1976. The radiocarbon results are given as $\Delta$ values relative to $95 \%$ of NBS oxalic acid 
activity, age-corrected to 1950 and isotopically-corrected to $\delta^{1: 3} \mathrm{C}=-25 \%$ (PDB). Some values have been published previously, in particular, those listed in Tables 1 through 14 (Bien et al, 1960, 1963a, 1963b, 1965; Bien and Suess, 1967). The author has re-evaluated the counting data for the years 1957 to 1969 and revised background and standard values. In a very few cases, counting data for certain samples were found to be invalid due to electronics or detector malfunctions. Such data, which had been included in previously-published tables have been omitted; in a few other cases, previously-unpublished results from 1957 to 1969 have been added here.

The measurements were carried out with an accuracy considered adequate for our purpose. A higher precision could have been achieved by using larger water samples and/or longer counting times. This, however, appeared uneconomical, time consuming, and unnecessary for the purpose of deducing basic oceanographic parameters. Likewise, measurements of the total content of inorganic carbon were considered superfluous.

As can be recognized easily, the data show an impressive minimum along the equator and in other regions of the Pacific Ocean where upwelling occurs. Consistently high $\Delta$ values are observed in the central areas of the large Pacific gyres. Evaluation of these data in terms of rates of ${ }^{1+} \mathrm{C}$-exchange, circulation, and upwelling is planned and will be published elsewhere. In this connection, continuation of these measurements for many more years appears desirable. With no further release of large ${ }^{1 .} \mathrm{C}$ quantities into the atmosphere the concentration differences in surface water should gradually disappear. Because of lack of funds we were not in a position to continue this program but fortunately Geosecs plans to continue these observations.

\section{ACKNOWLEDGMENTS}

Many people deserve credit for their contribution in obtaining the data for this work. Much credit is due to G S Bien, who until 1971 was in charge of the technical operations of the laboratory and who participated in most of the early work in the field of seawater radiocarbon. I wish to thank the following people who collected samples: A Bates, R Bellegay (for C S Wong), G S Bien, D Brown, J L Coatsworth, H Craig, F Dixon, I) Kellogg, J A Knauss, W L Kosiba, J B Lawson, P Liebert\%, R L Michel, I) Palmer, N W Rakestraw, I Rearclon, J I. Reid, R Verdery, and S E Wardanni. The following persons performed technical operations and assisted in the measurements: G S Bien, S Chillcott, S Divis, Cis Hutto, I I, S Jackson, L Milne, L J Pandolfi, W F Cain and D) Hasha. I) $\mathrm{K}$ Sullivan designed, constructed, and maintained the clectronic equipment used in the later years of the project. H E Suess instigated and supervised this work. From 1958 to 1971 the collection of the water samples was funded by the U S Atomic Energy Commission. operations of the Ia Jolla Radiocarbon laboratory are financed by 
grants from the National Science Foundation, Earth Sciences Division, EAR76-22623 and predecessor grants to H E Suess.

\section{PRESENTATION OF DATA}

The measurements are given in several data tables. Each table gives results for one cruise, or sometimes for more than one cruise if only a few samples were collected on each cruise from the same approximate period of time. The tables are chronologically ordered, from earliest sampling to most recent. The tables which follow contain several columns of information that can be used in the interpretation of the radiocarbon data. An asterisk in place of a value indicates that the quantity was not measured or was otherwise unavailable. When $\delta^{13} \mathrm{C}$ was not measured, a value of $0.0 \%$ was used in tables 1 through 15 , a value of $+1.2 \%$ in tables 16 through 26. Some column headings are described below:

$$
\begin{aligned}
\text { Depth }= & \text { sampling depth in meters below sea surface. Sample des- } \\
& \text { ignated as being from Om may actually be from a few } \\
& \text { meters below the sea surface. } \\
\text { Salinity }= & \text { as measured on a conductance bridge salinometer } \\
\sigma_{\mathrm{t}}= & \text { difference, } / / 6 \text {, between density of water of given tem- } \\
& \text { perature ancl salinity at } 1 \mathrm{~atm} \text { pressure and density of } \\
& \text { pure water at } 4^{\circ} \mathrm{C} \text { and } 1 \mathrm{~atm} \text { pressure. This is the ac- } \\
& \text { cepted method of expressing the density of seawater. } \\
& \text { Values were calculated by the author from Knudsen } \\
& \text { (1953) and Matthews (1932) or from U S Navy Hydro- } \\
& \text { graphic Office }(1956) \text {, which present tables of value for } \\
& \text { calculating } \sigma_{\mathrm{t}} \text { for a given temperature and salinity. }
\end{aligned}
$$

\section{REFERFNCES}

Bien, G S, Rakestraw, N W, and Suess, H E, 1960, Radiocarbon concentration in Pacific Occan water: Tellus, v 12, p 436-443.

1963a, Radiocarbon dating of deep water of the Pacific and Indian Oceans: Inst Oceanog Bull, v 16, p 12-16. Also in: Radioactive dating, IAEA, Vienna, p $159-173$.

1963b, Natural radiocarbon in the Pacific and Indian Oceans: Nuclear Sci Ser Rept No. 38, Pub 1075, NAS-NRC, Washington, DC, p 152-160.

1965, Radiocarbon in the Pacific and Indian Oceans and its relation to deep water movements: Internatl conf of radiocarbon and oceanog, 6th, Proc, v 10, Supp, p R25-R37.

Bien, G S and Suess, H E, 1967, Transfer and exchange of ${ }^{14} \mathrm{C}$ between the atmosphere and the surface water of the Pacific Ocean: Radioactive dating and methods of low level counting, IAEA, Vienna, p 105-115.

Broccker, W S, Gerard, R, Ewing, M, and Heczen, B C, 1960, Natural radiocarbon in the Atlantic Ocean: Jour Geophys Research, v 65, p 2903-2931.

Broecker, W S and Olson, E A, 1959, Lamont radiocarbon measurements VI: Am Jour Sci Radiocarbon Supp, v 1, p 111-132.

Craig, H, 1958, A critical evaluation of radiocarbon techniques for determining mixing rates in the oceans and the atmosphere: UN internatl conf on peaceful uses of atomic energy, 2d, Proc, p 503-518.

Knudsen, M, 1953, Hydrographical tables: Copenhagen, Tutein og Koch, repr.

Linick, T W, 1975, Uptake of bomb-produced carbon-14 by the Pacific Ocean: PhD dissert, Univ California, San Diego, $255 \mathrm{p}$. p $19-48$.

1977, La Jolla natural radiocarbon measurements VII: Radiocarbon, v 19, 
Matthews, I) J, 1932, Tables for the determination of the density of seawater under nomal pressure. $\sigma_{t}$ : Conseil permanent internatl exploration de la mer, Copen-
hagen, Andr Fred Host et Fils.

Rafter, I A, 1968, Carbon- 44 variations in nature, Part $3-{ }^{14} \mathrm{C}$ measurements in the South Pacific and Antarctic Oceans: New Zealand Jour Sci, v 11, p 551-589.

Rafter, I A and O'Brien, B J, 1970, Exchange rates between the atmosphere and the ocean as shown by recent C-14 measurements in the South Pacific: Radiocarbon variations and absolute chronology, I U Olsson (ed), Nobel symposium XII Proc, Uppsala, Sweden, p 355-377.

1972, ${ }^{14} \mathrm{C}$ measurements in the South Pacific Ocean-a recalculation of the exchange rates between the atmosphere and the ocean: 8th internatl conf on radiocarbon dating, Proc, v 1, Royal Soc New Zealand, p Ci7-C42.

Revelle, R and Suess, H E, 1957, Carbon dioxide exchange between atmosphere and ocean and the question of an increase of atmospheric $\mathrm{CO}_{2}$ during the past decades: Tellus, v 9, p 18-27.

Suess, H E, 1970, Bristlecone pine calibration of the radiocarbon time scale $5200 \mathrm{BC}$ to the present: Radiocarbon variations and absolute chronology, I U Olsson (ed), Nobel symposium XII Proc, Uppsala, Sweden, p 303-313.

U S Navy Hydrographic office, 1956, Tables for rapid computation of density and electrical conductivity of seawater: Hydrographic Office Pub No. 619, Dept of the Navy, Washington, DC. 

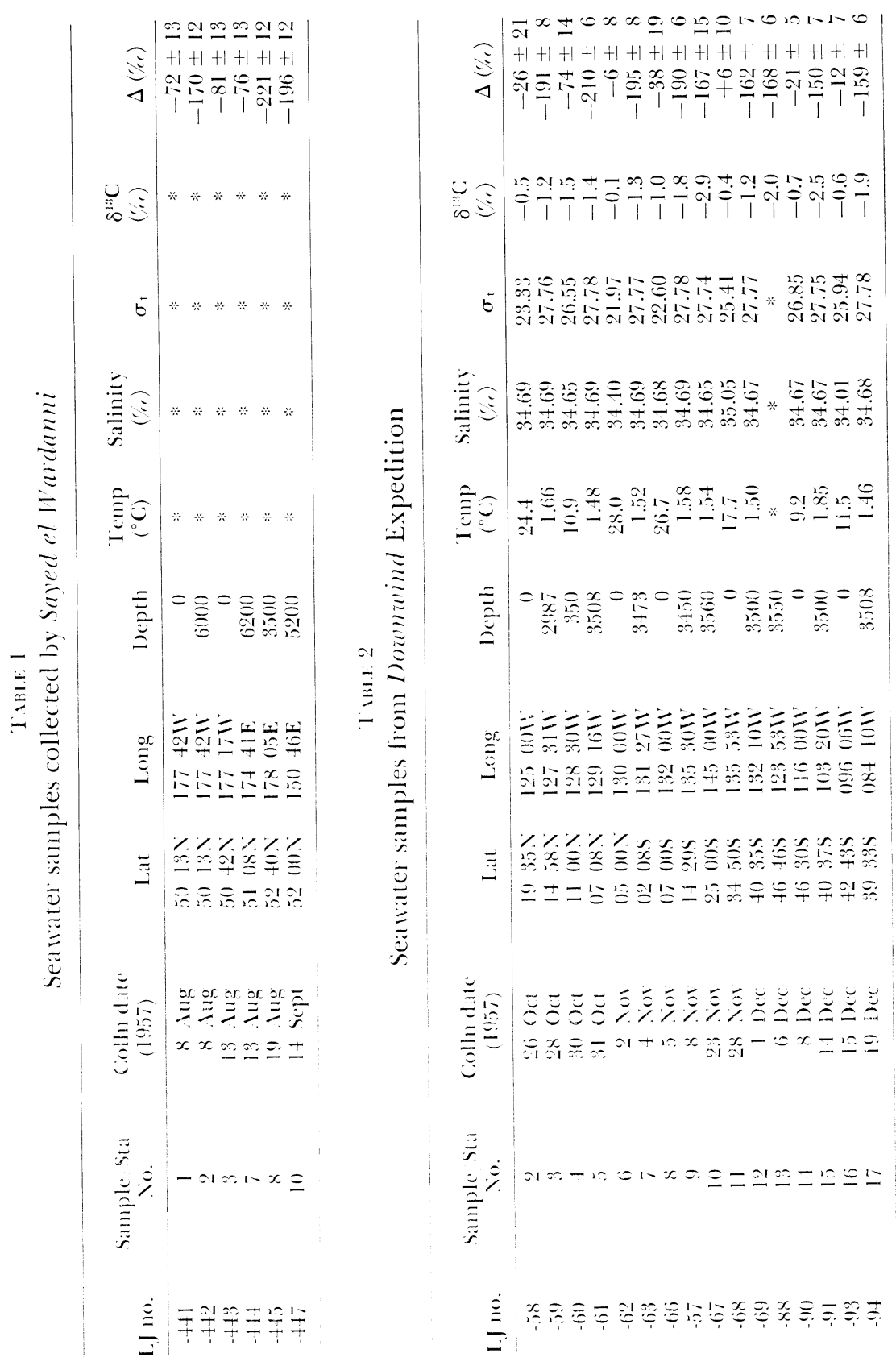

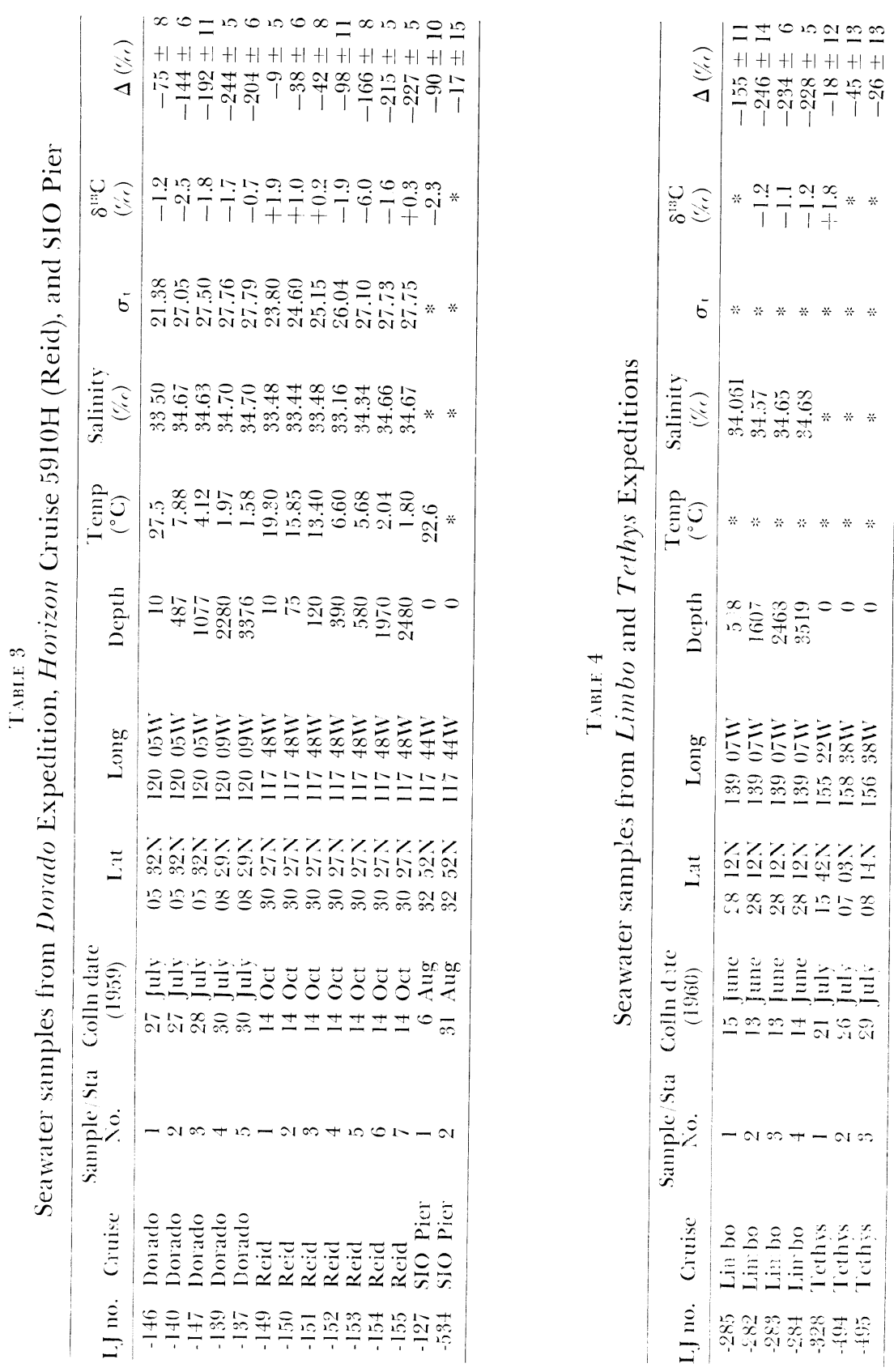


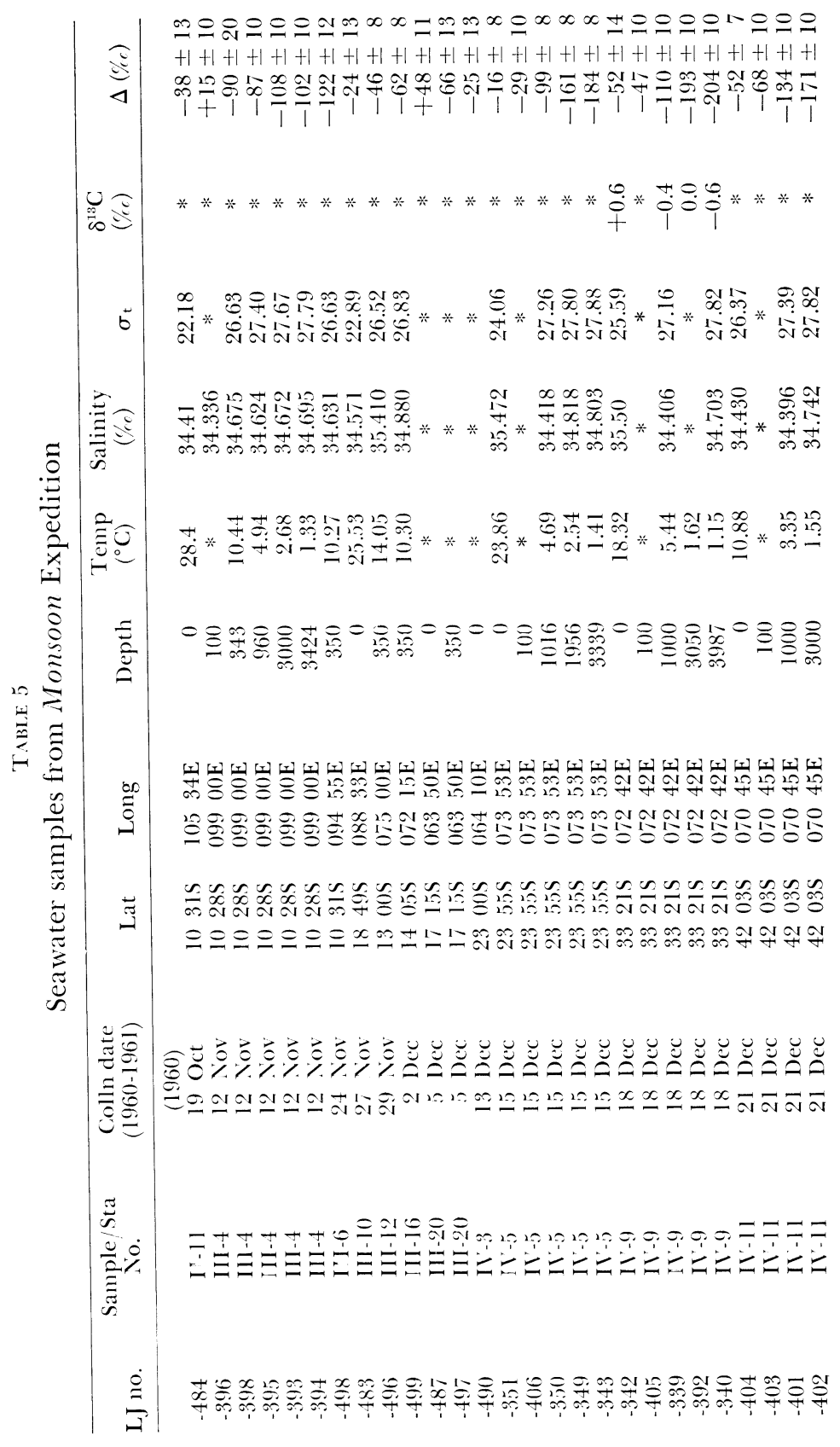




\begin{tabular}{|c|c|}
\hline 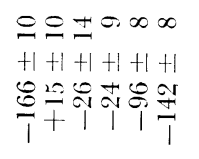 & 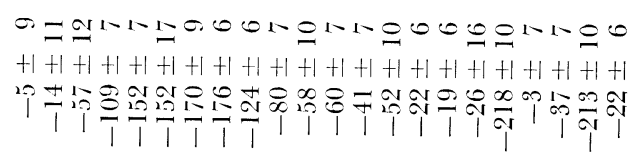 \\
\hline$* * * * * *$ & ** \\
\hline 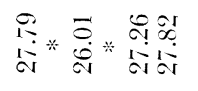 & 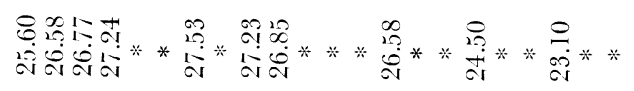 \\
\hline 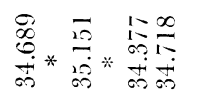 & 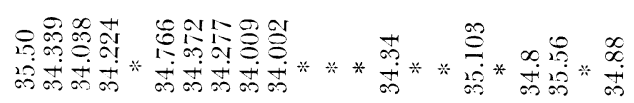 \\
\hline 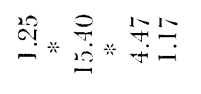 & 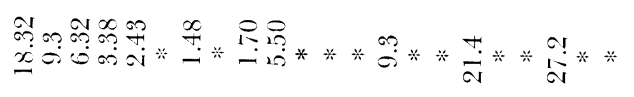 \\
\hline 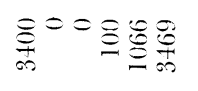 & 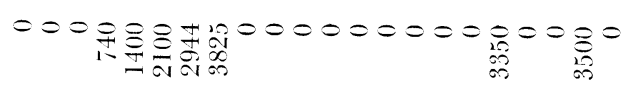 \\
\hline 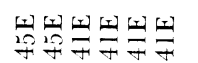 & 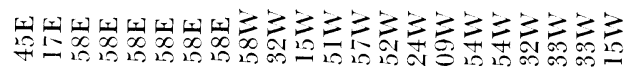 \\
\hline 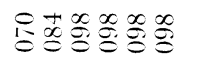 & o \\
\hline $\sin _{\infty}^{\infty} \infty \infty$ & 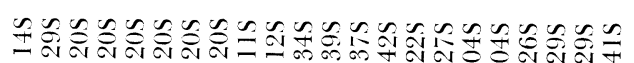 \\
\hline 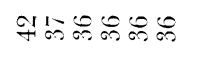 & 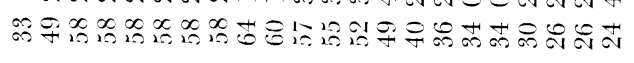 \\
\hline \multicolumn{2}{|c|}{ 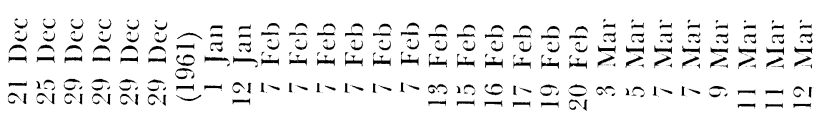 } \\
\hline 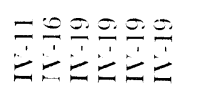 & 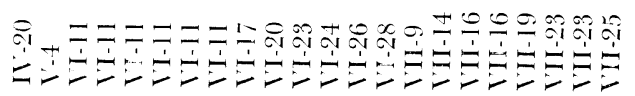 \\
\hline 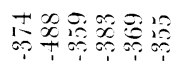 & 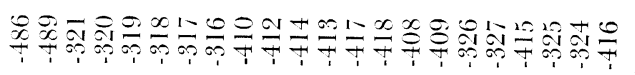 \\
\hline
\end{tabular}



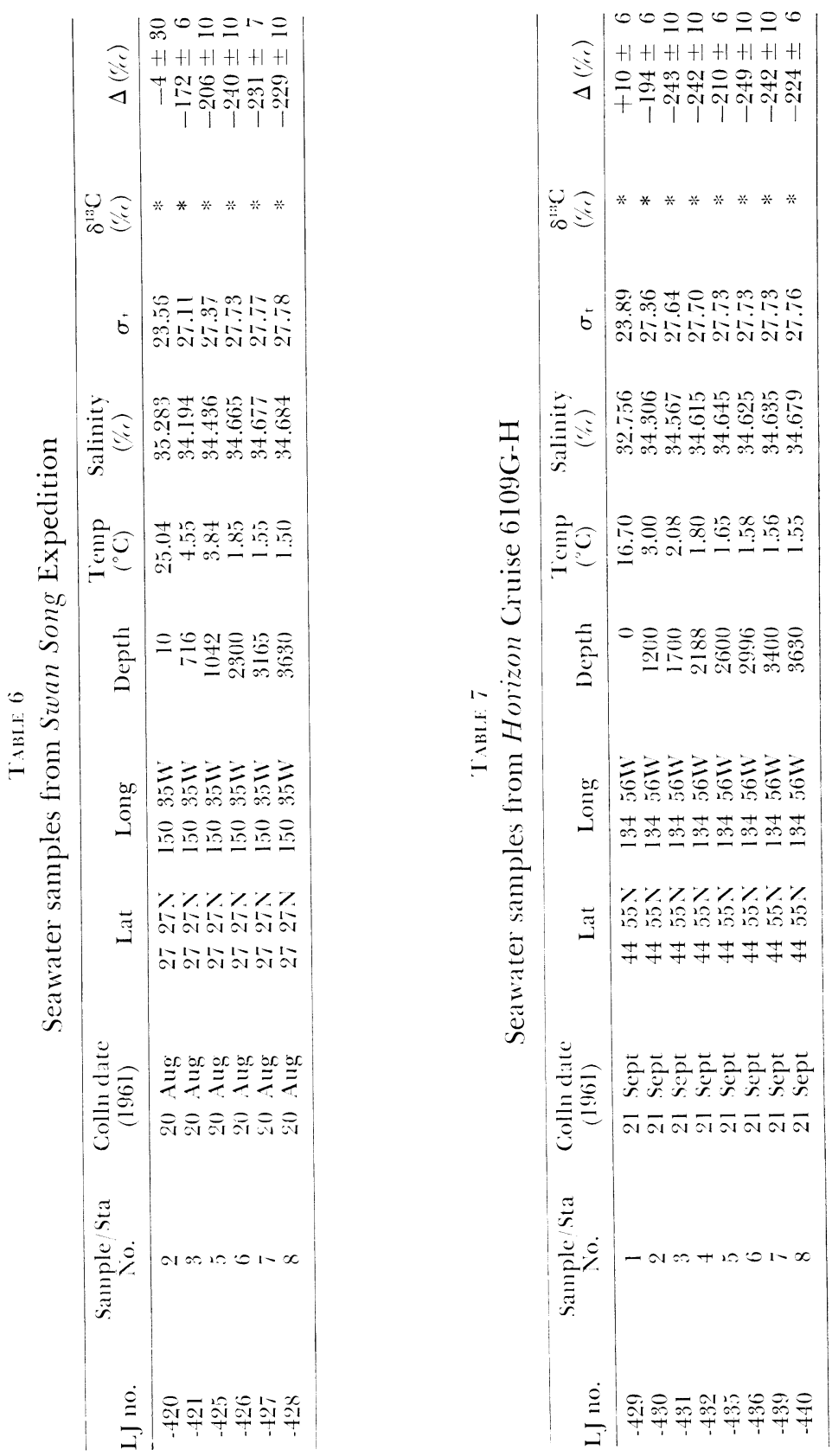

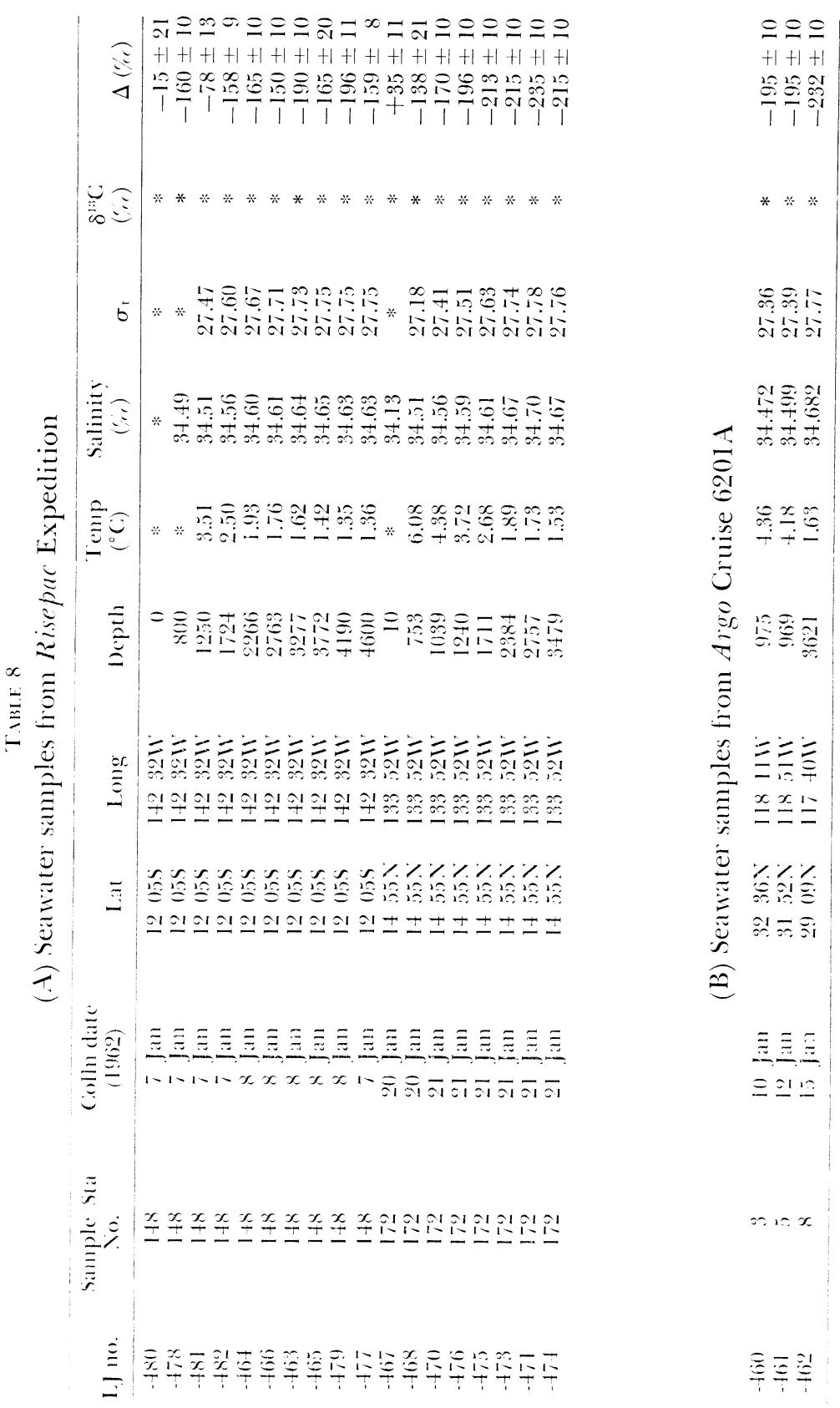


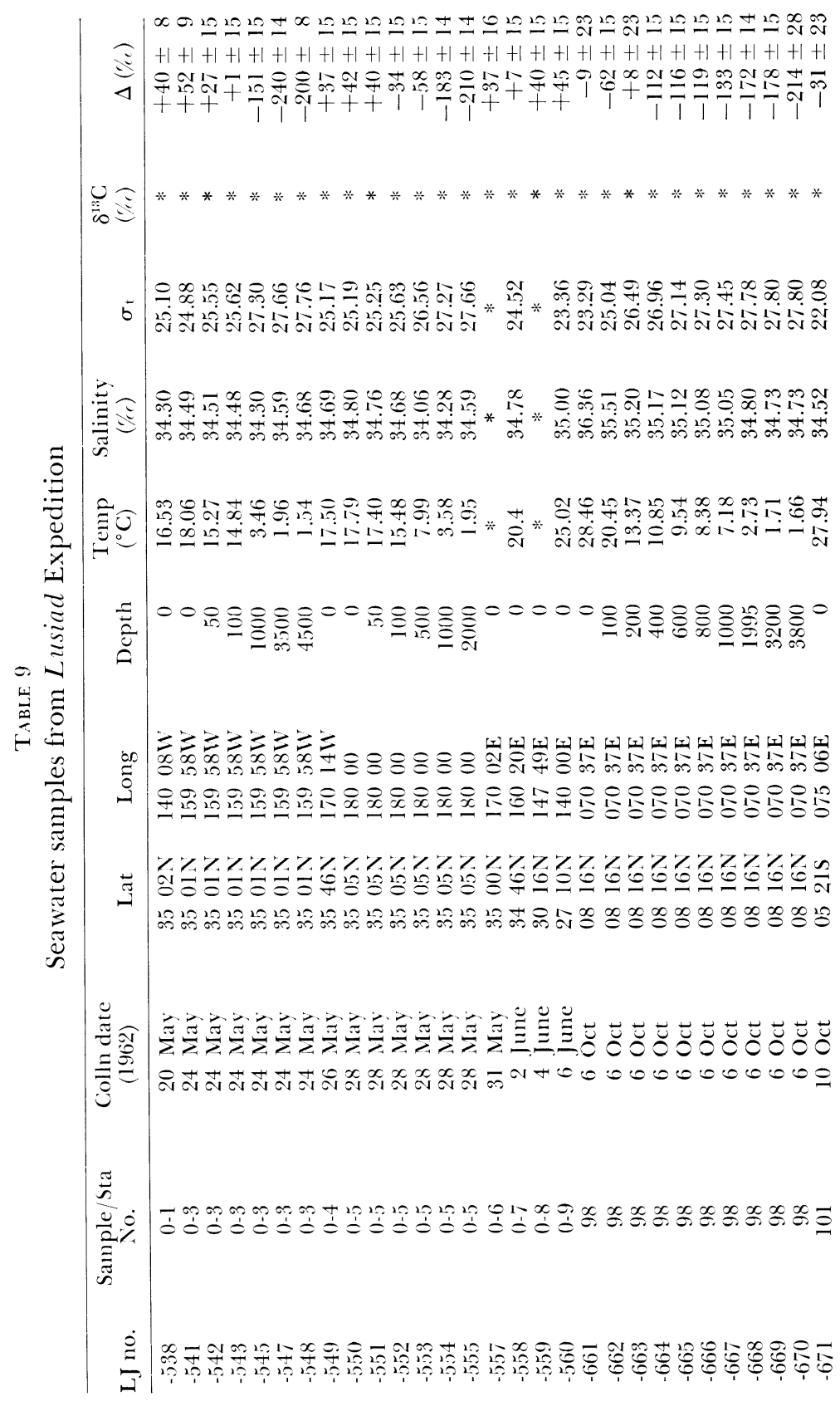




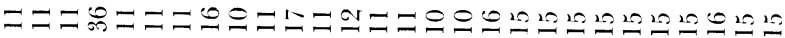
$+1+1+1+1+1+1+1+1+1+1+1+1+1+1+1+1+1+1+1+1+1+1+1+1+1+1+1+1$

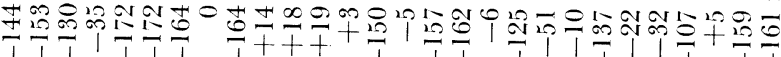

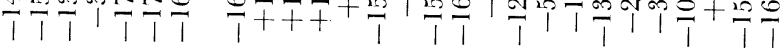

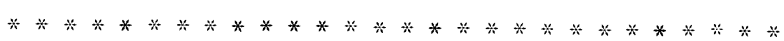

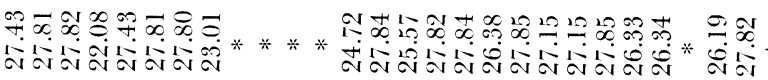

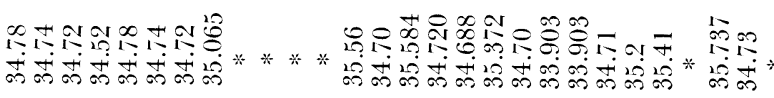

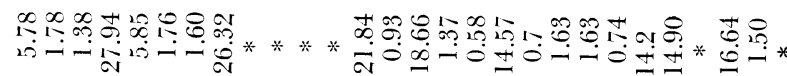

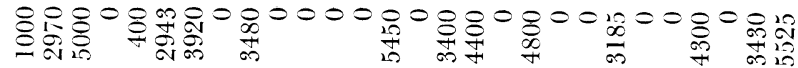

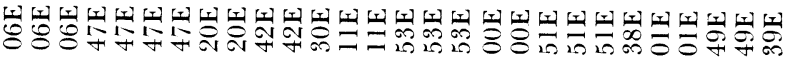

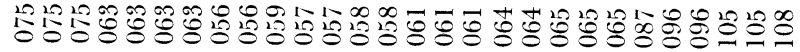

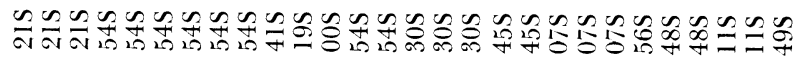

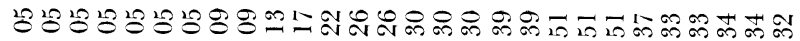

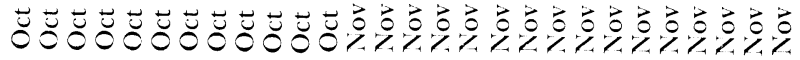

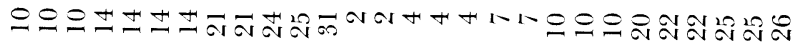

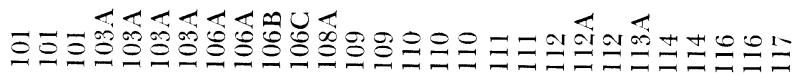

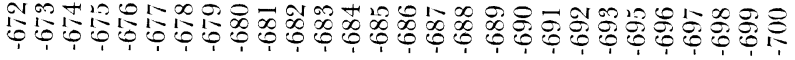



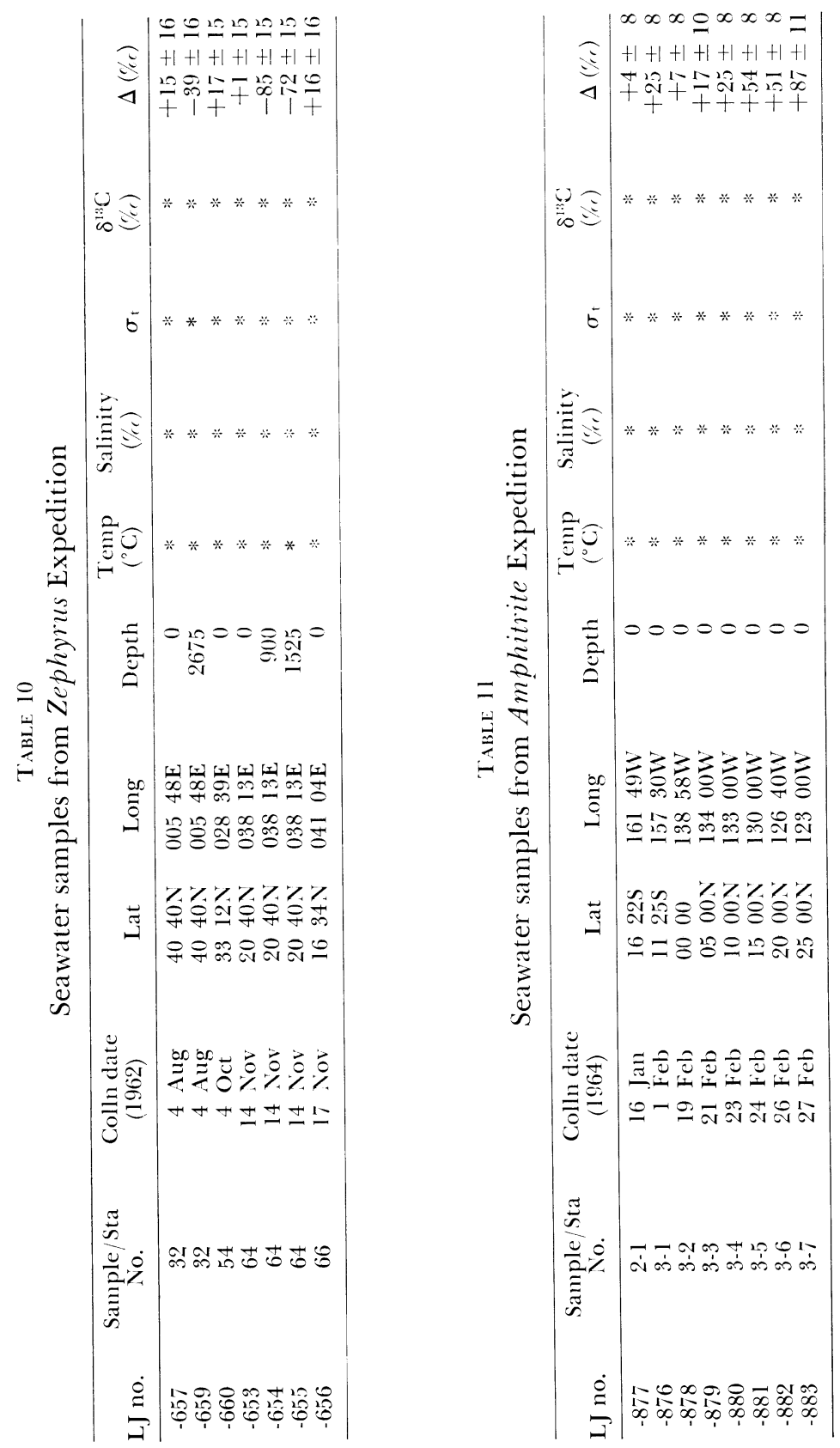


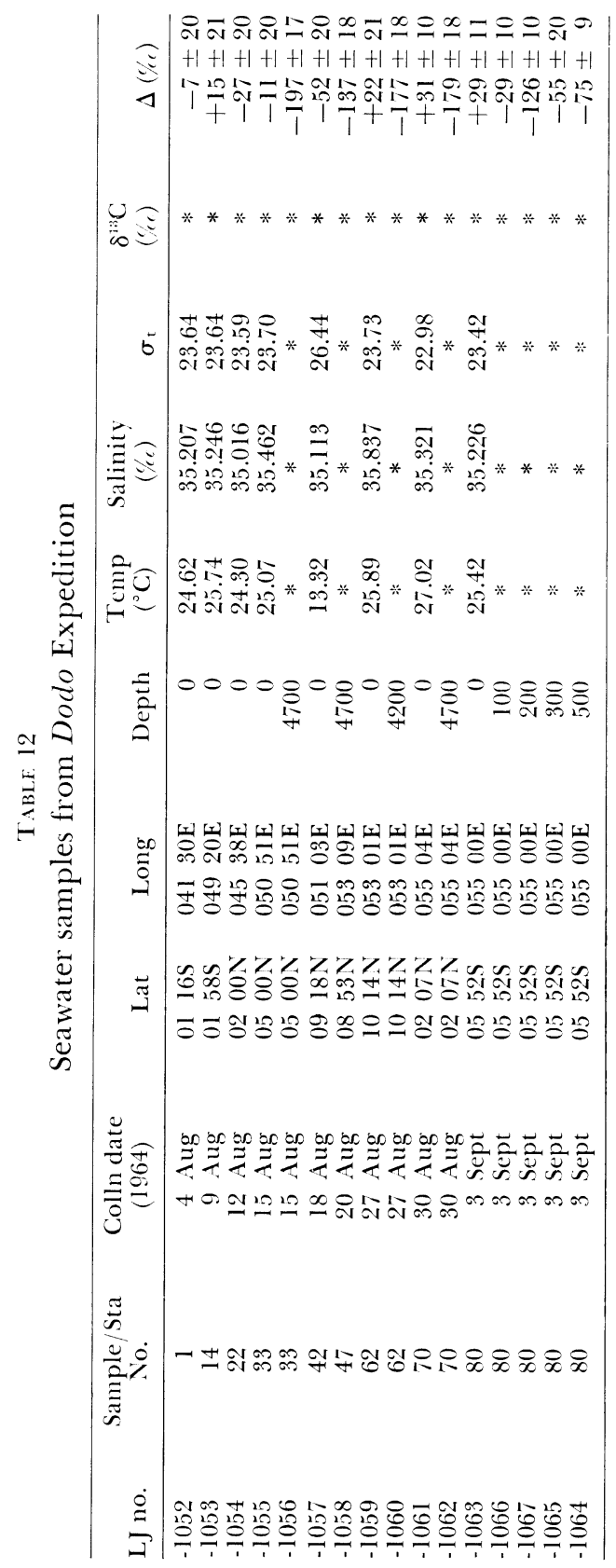




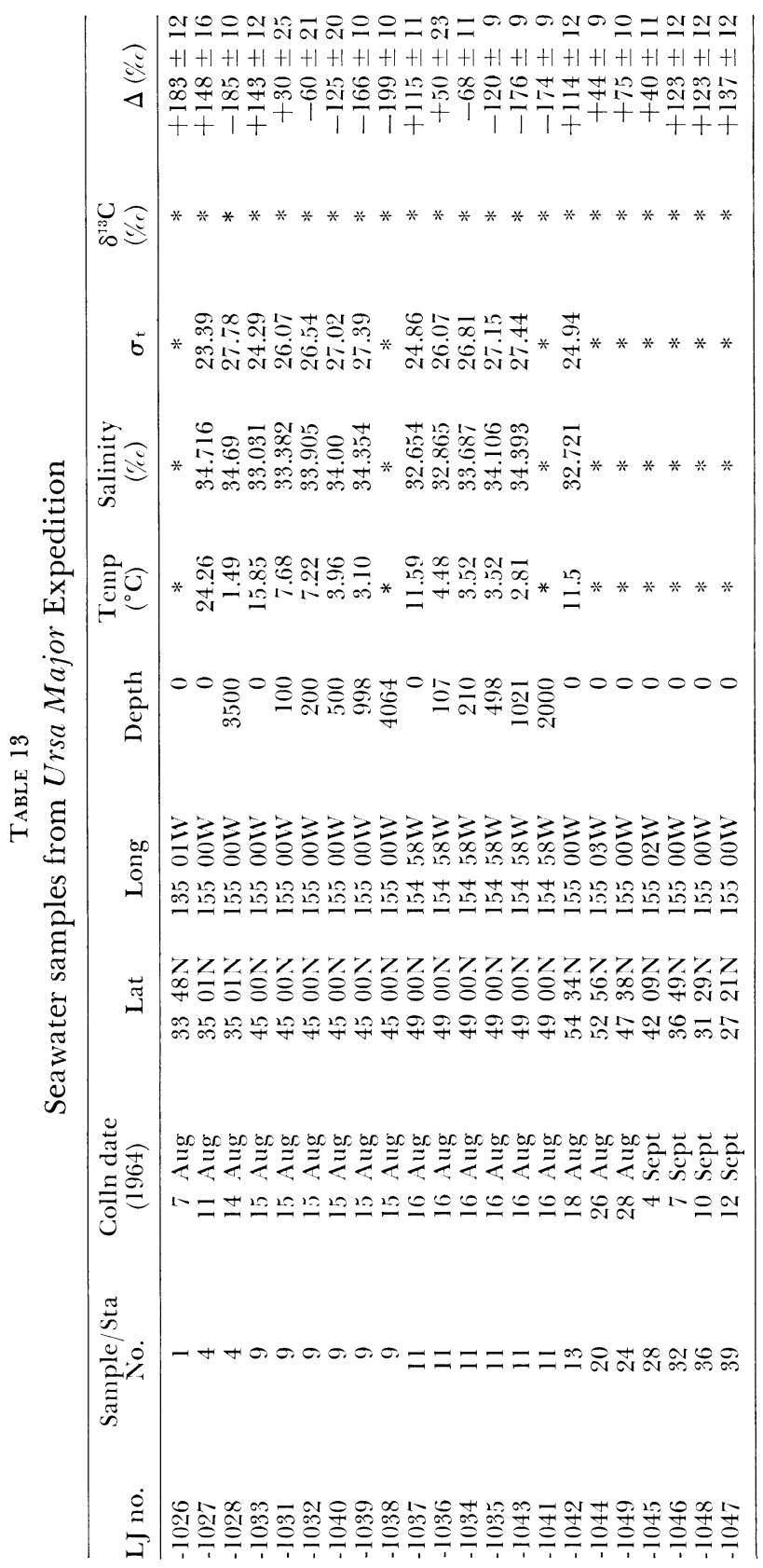




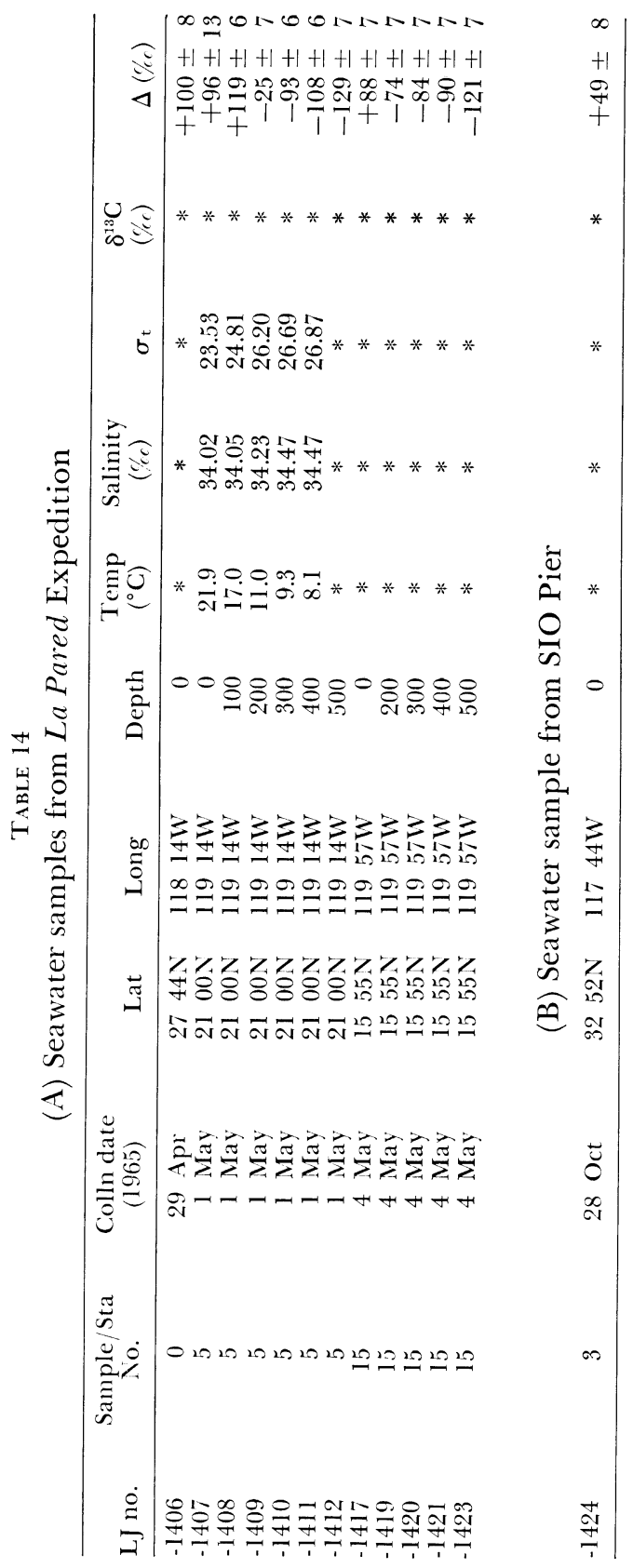




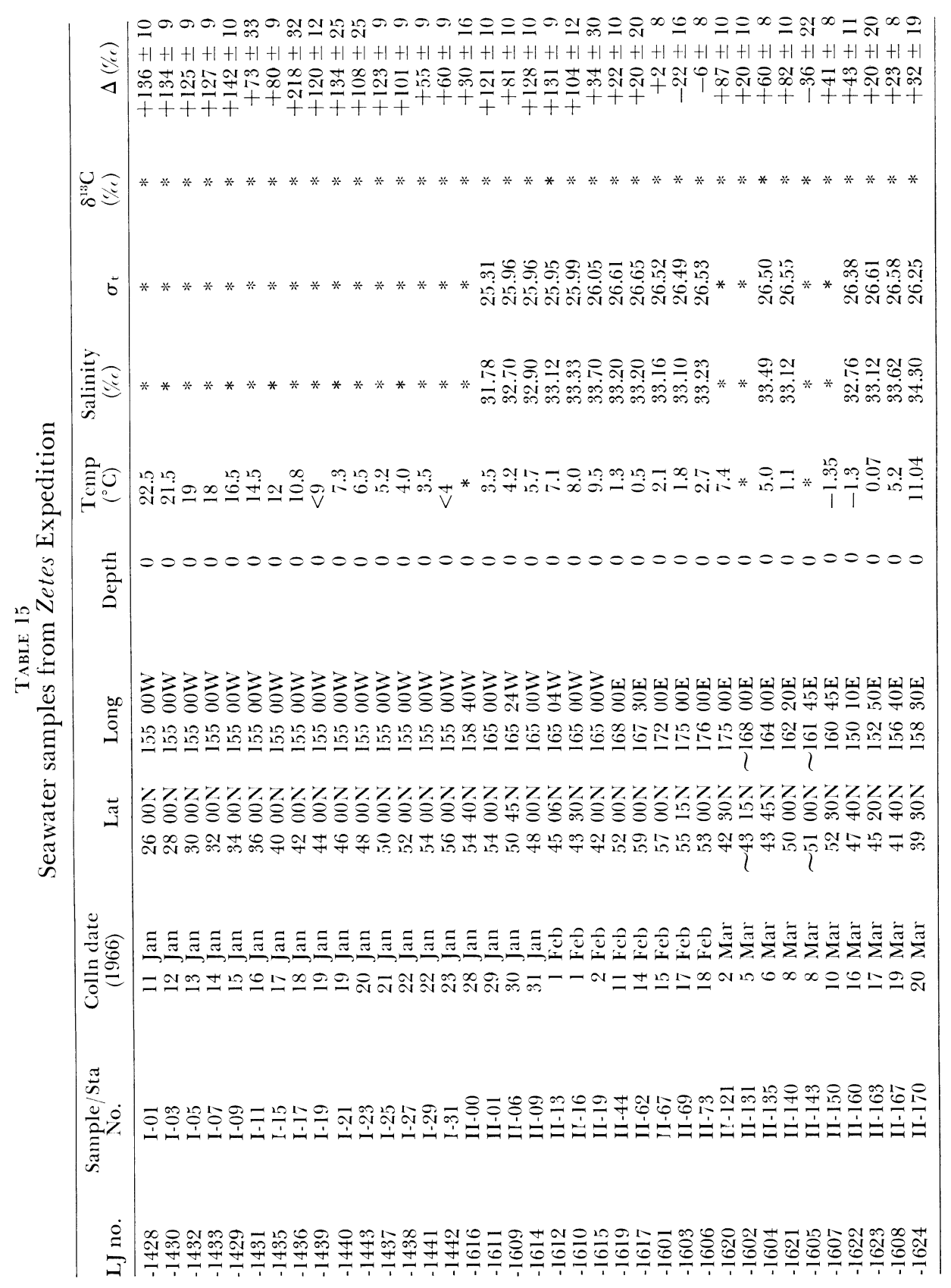



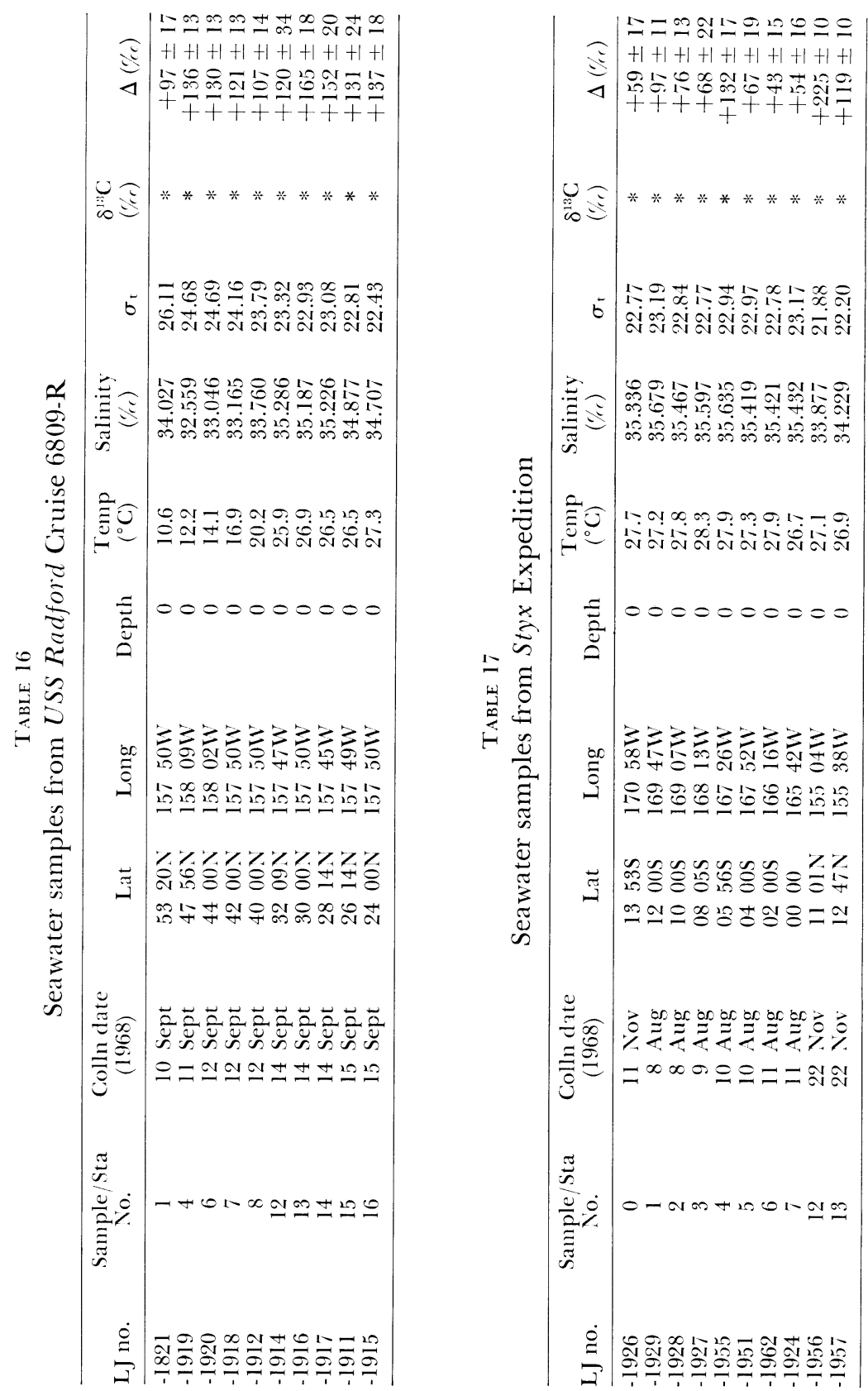


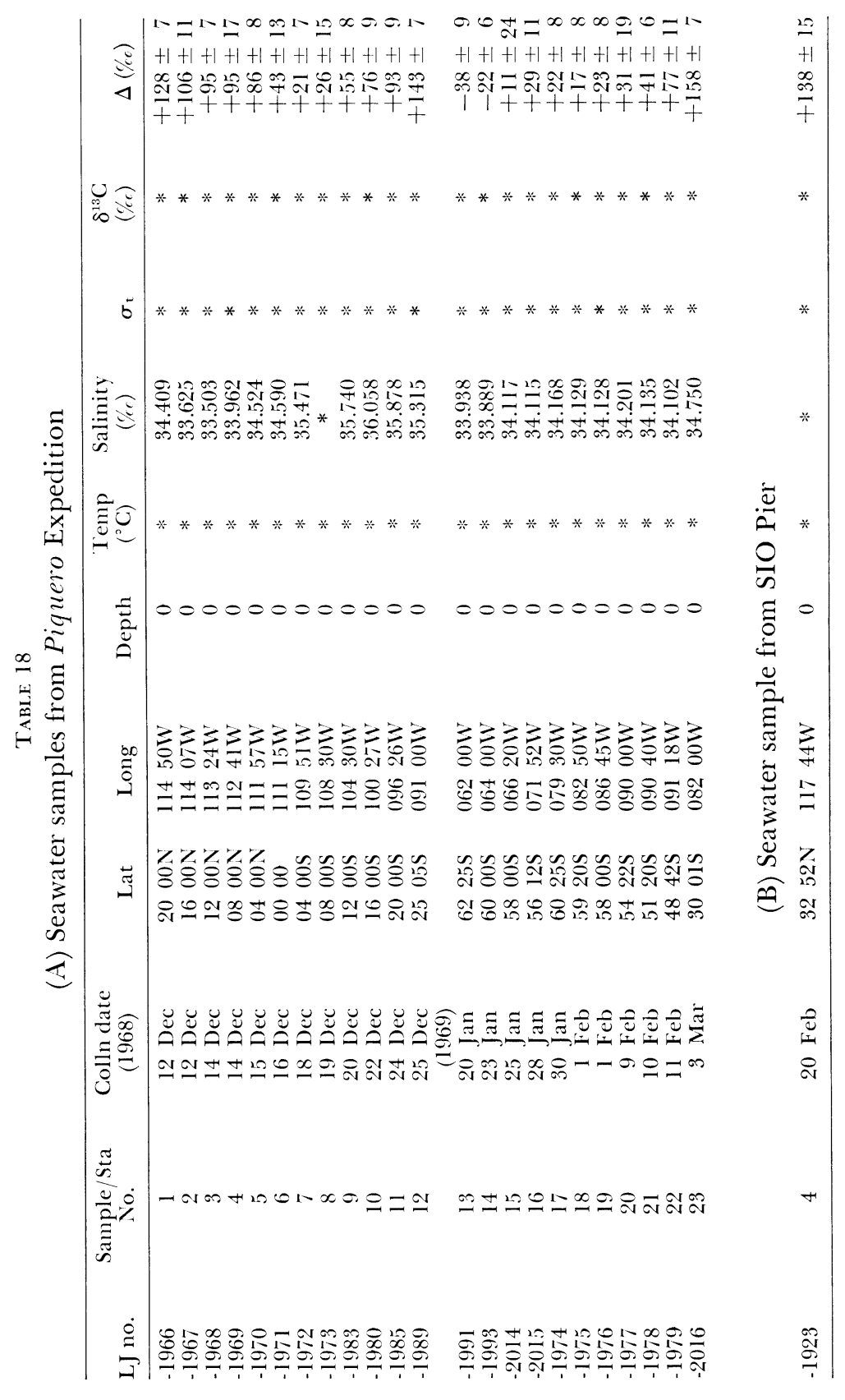




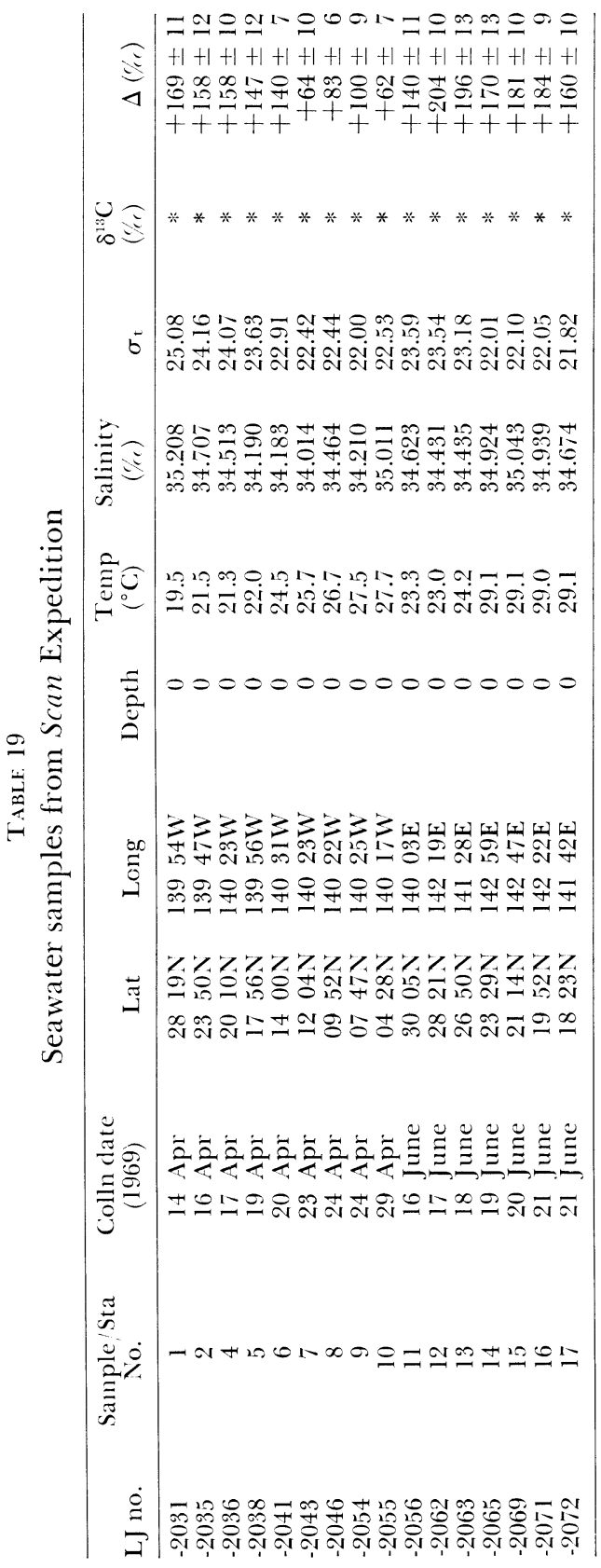



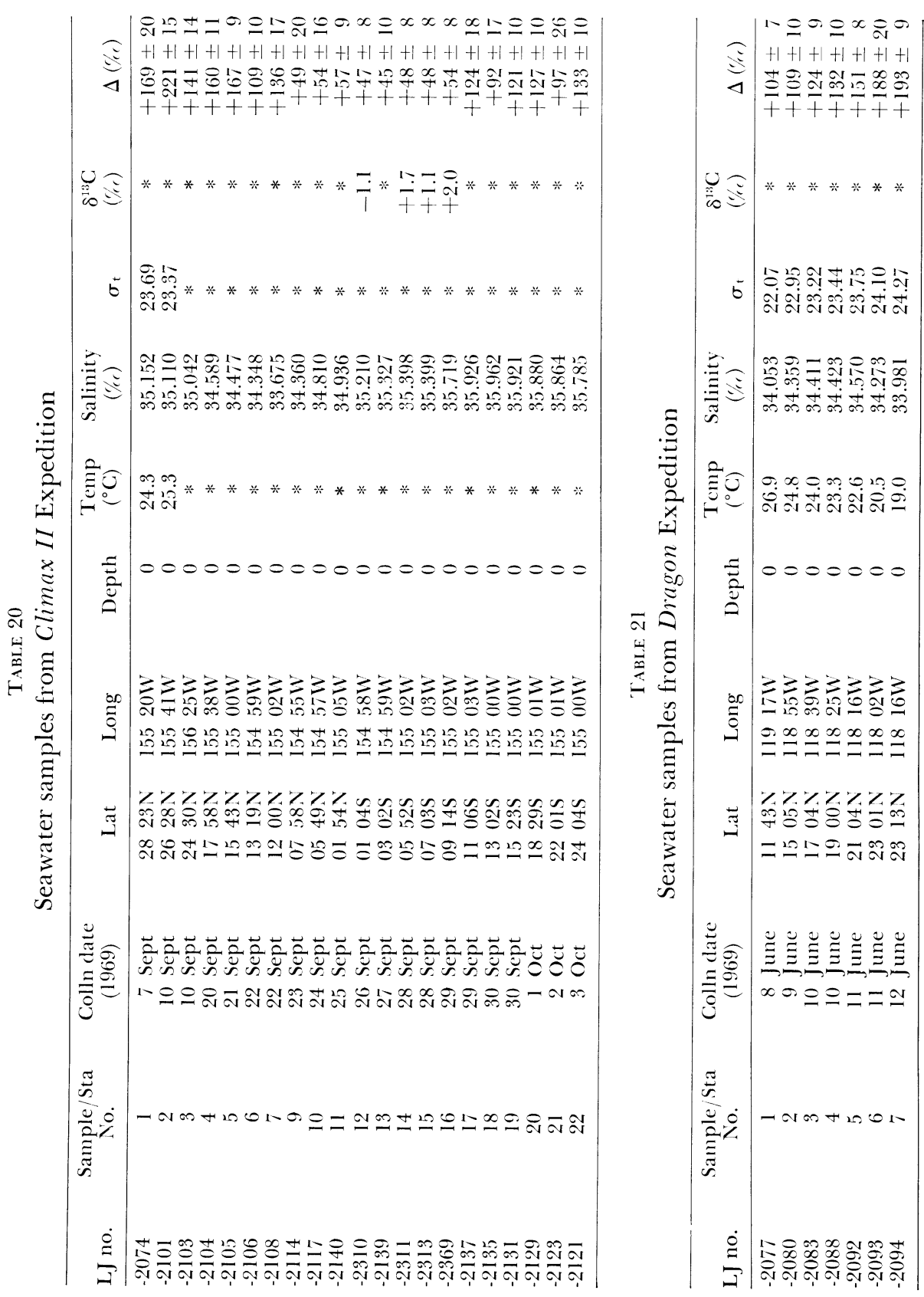


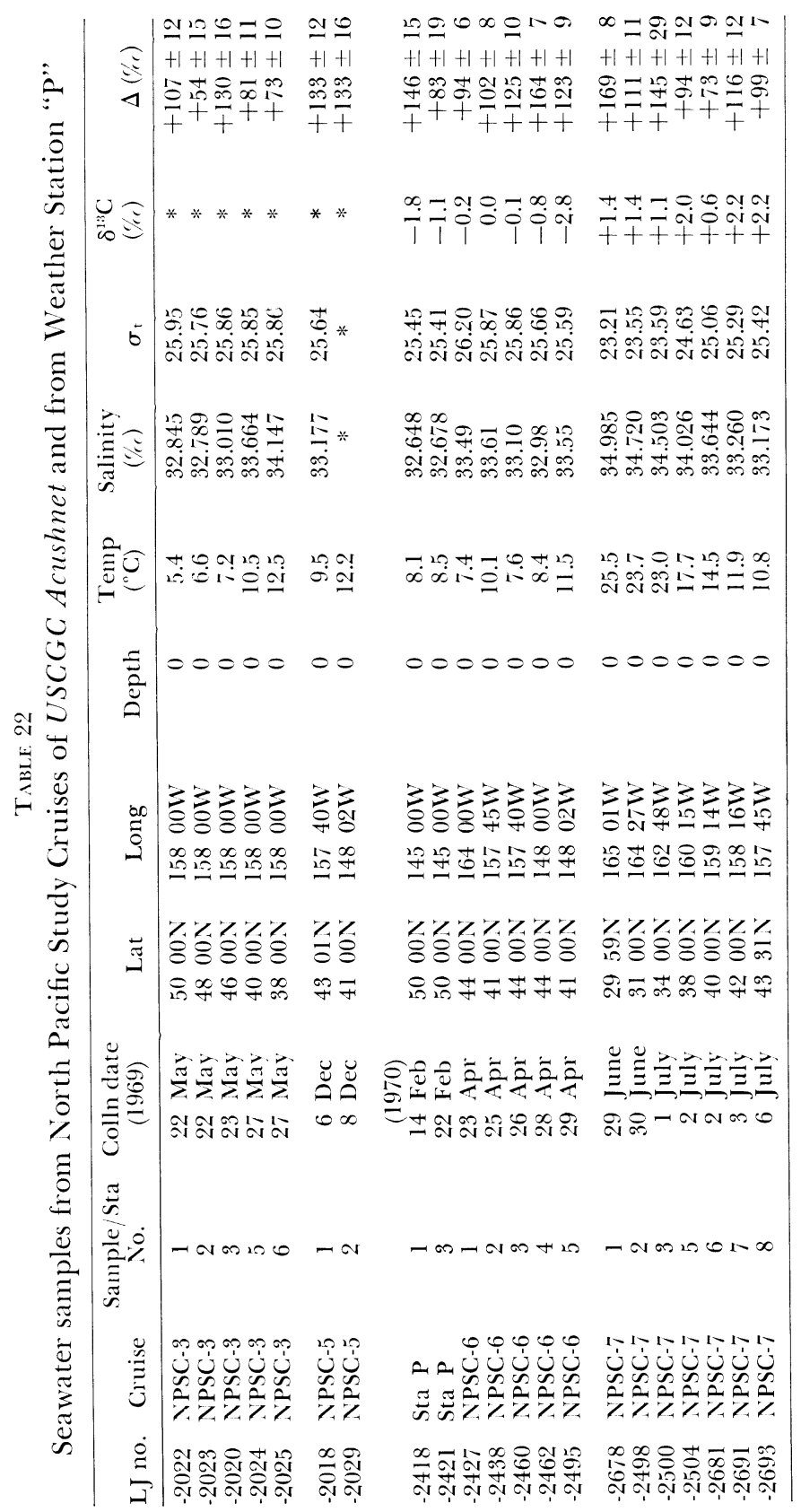




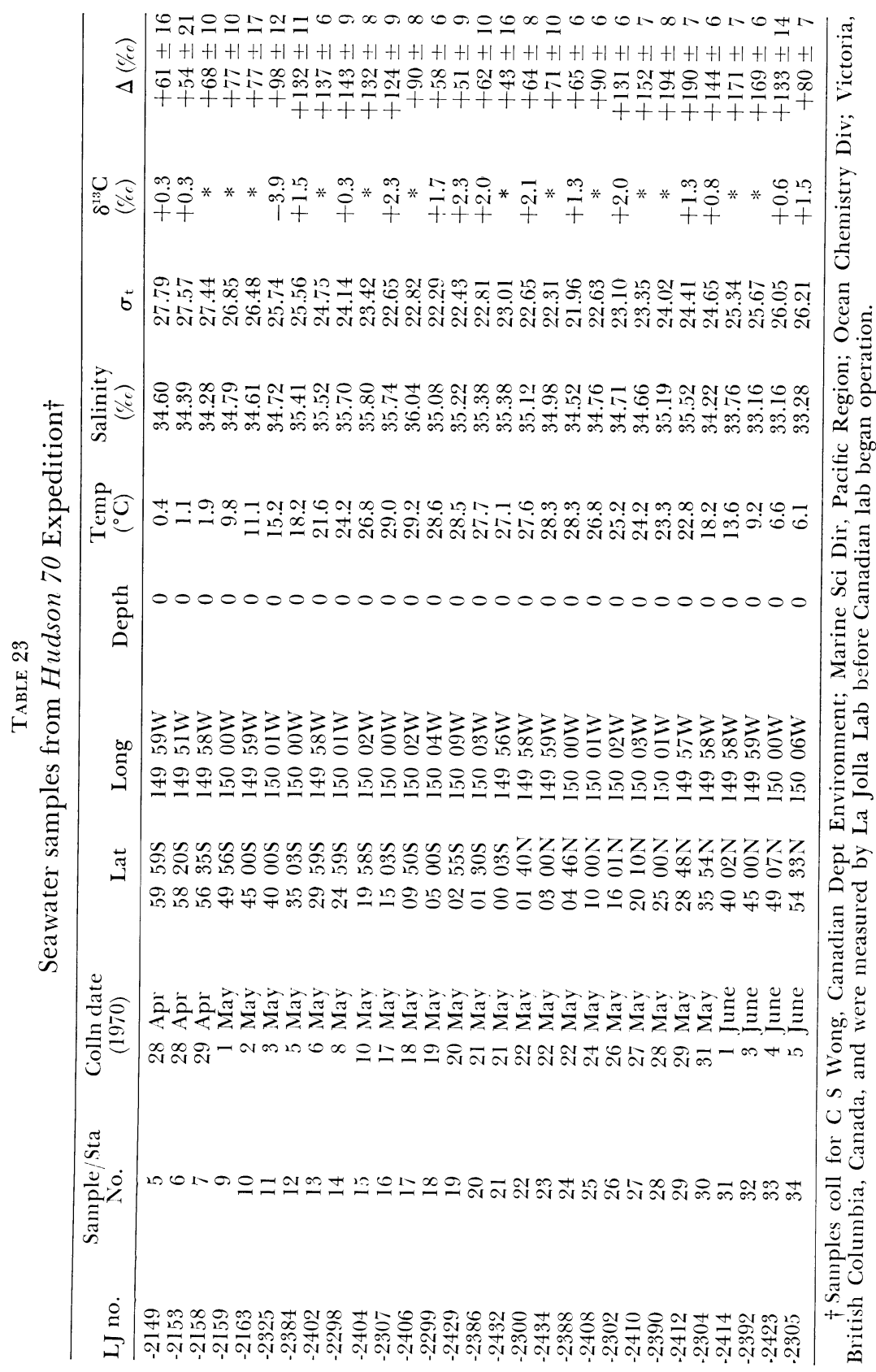




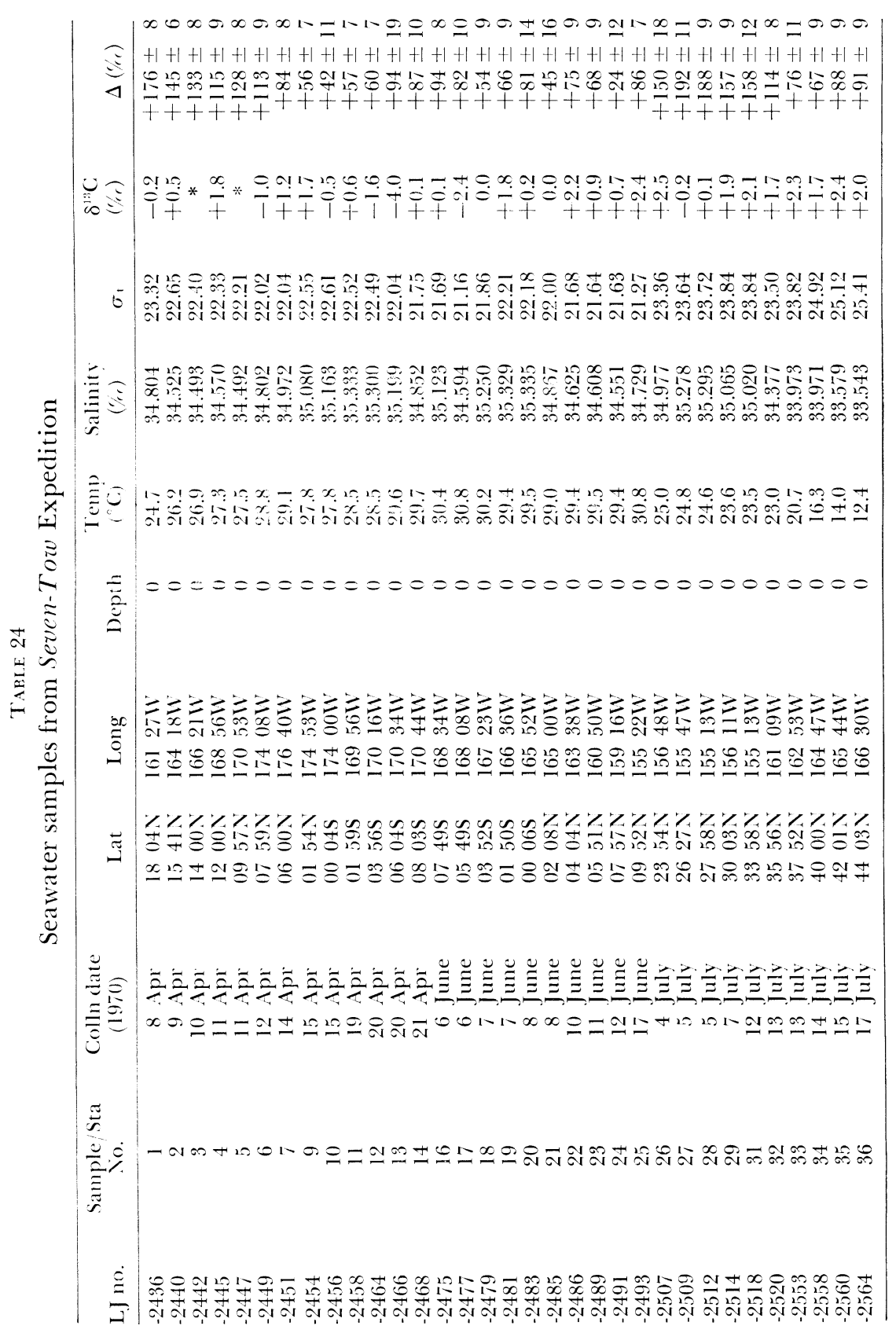




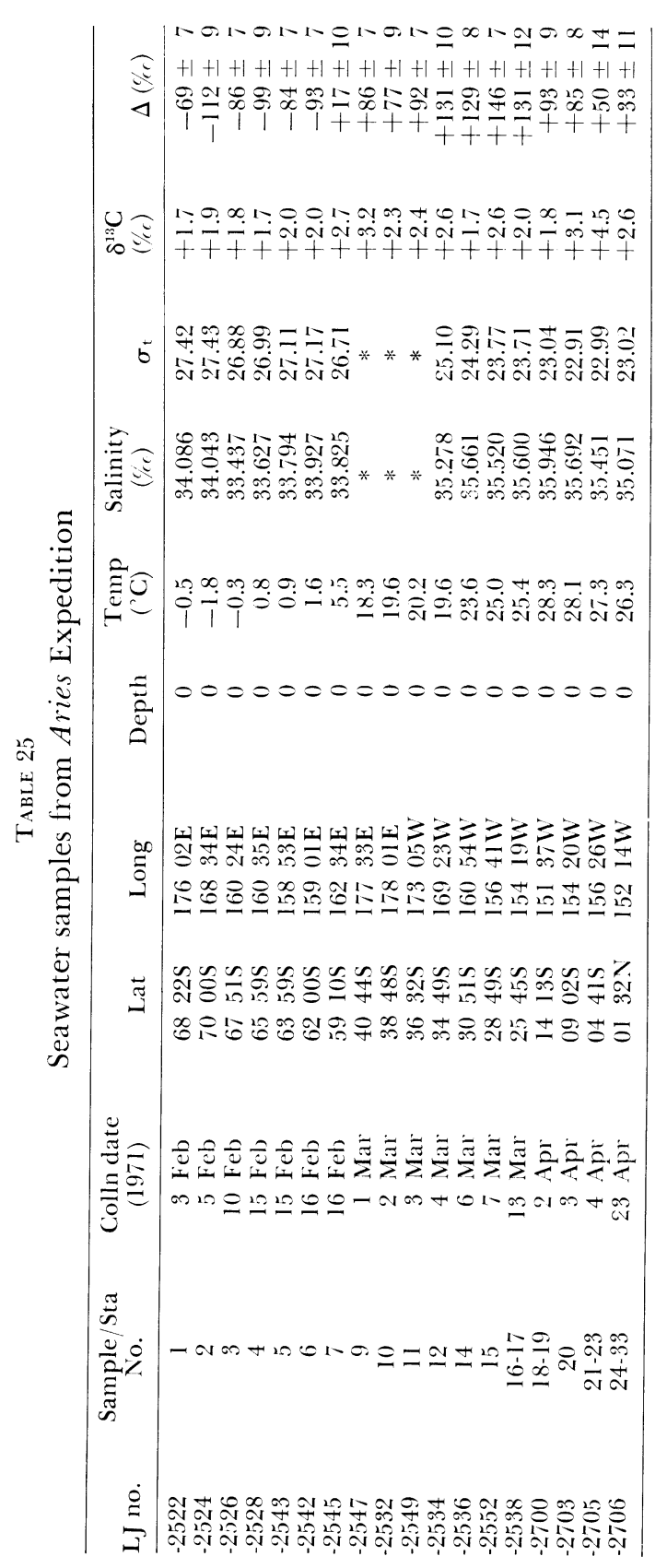




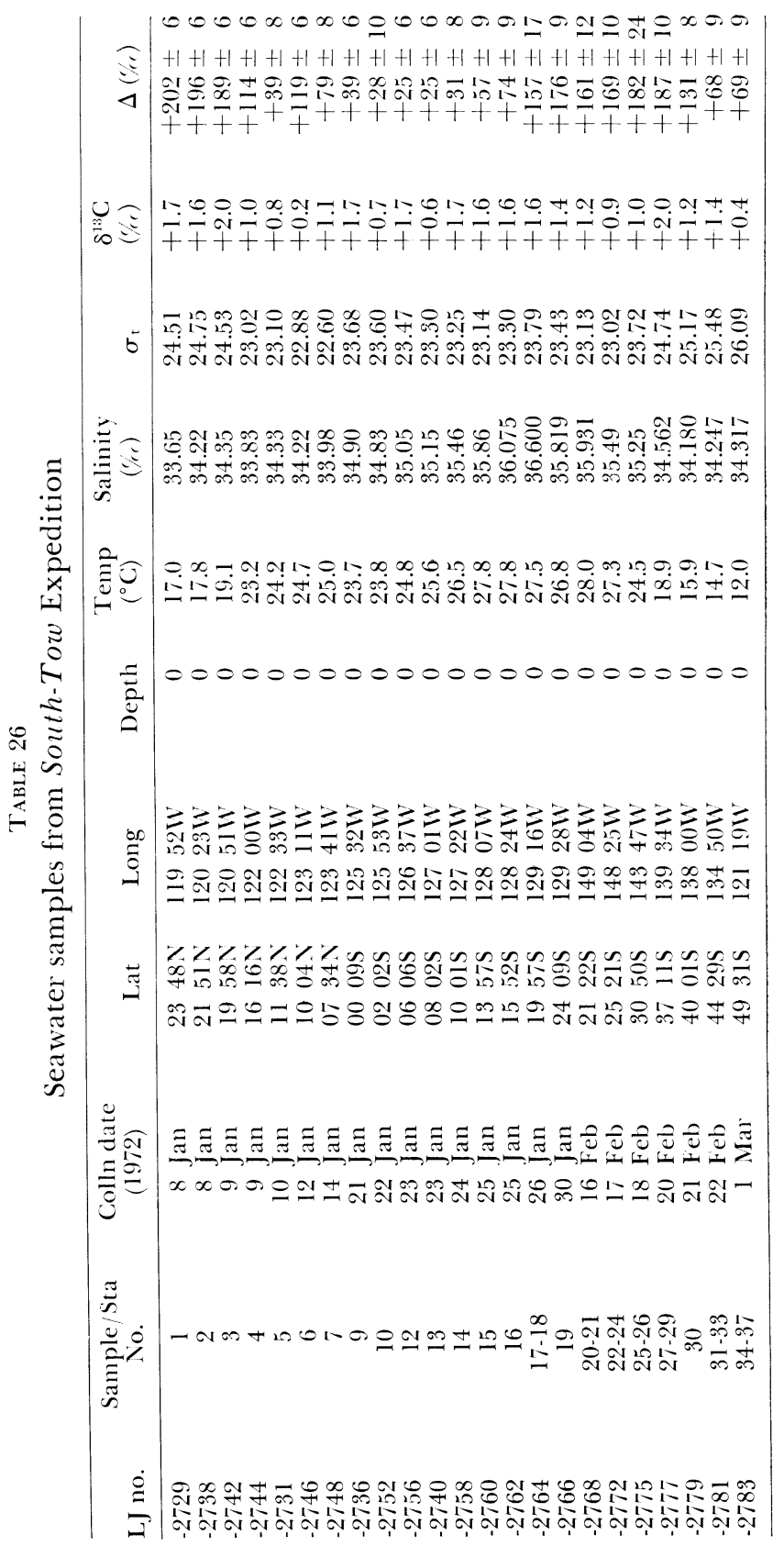

